\title{
Protocolo y TIC: las series de TV como herramienta docente Protocol and ICT: TV shows as a learning tool
}

\author{
Daniel Delmás Martín ${ }^{1}$ \\ Universitat Jaume I de Castellón \\ danieldelmasmartin@gmail.com
}

\section{Resumen}

La docencia en el s. XXI va a cambiar radicalmente. A finales del siglo pasado, con el nacimiento de internet, surgen las Tecnologías de la Información y la Comunicación (TIC) que cambian completamente la vida de las personas. Dichas tecnologías han de entrar en las aulas. Este trabajo es fruto del esfuerzo por introducir las TIC en las aulas con el fin de mejorar el proceso de enseñanza-aprendizaje para los estudiantes de protocolo.

Los pasados enero-marzo de 2018 en la clase de protocolo y organización de eventos de la Universitat Jaume I de Castellón, se convirtieron las series de TV en material docente con el fin mejorar el aprendizaje de los alumnos de los conceptos de esta materia. Este trabajo presenta el método empleado y los resultados obtenidos.

Palabras claves: protocolo, enseñanza, series de TV, TIC, proceso de enseñanza-aprendizaje

\section{Abstract}

Teaching in the 21th century is going to change radically. At the end of last century, with the Internet's birth, Information and Communication Technologies (ICT) arise to change people's lives. These technologies must enter the classrooms. This paper is the outcome of the effort to introduce ICT in the classroom to improve the student's understanding and learning of protocol concepts.

Last January-March 2018 in the events organizing and protocol subject at Jaume's I University in Castellón, we converted TV shows into teaching material in order to improve the learning process of the students in this theme. This paper presents the method and the results used.

\footnotetext{
${ }^{1}$ Licenciado en Publicidad y RRPP y especialista en eventos y protocolo. Más información curricular en: $\underline{\text { https://www.linkedin.com/in/danieldelmas y en www.danieldelmas.com }}$
} 
Keywords: protocol, teaching, TV shows, ICT, teaching-learning process.

\section{Sumario}

1. Introducción

2. Marco teórico

3. Desarrollo

4. Conclusiones

5. Bibliografía

\section{INTRODUCCIÓN}

Cuando a finales de la década de los años 60 los militares americanos inventaron internet, no creemos que fueran conscientes de lo que esa tecnología supondría para el mundo. Hoy en día las "www" son sinónimo de comunicación, y del acceso a grandes cantidades de conocimiento al alcance de prácticamente cualquiera. Estamos en la era del conocimiento digital.

A nivel educativo ese cambio ha generado una revolución pedagógica. No solo el propio internet, sino todas las llamadas Tecnologías de la Información y Comunicación (TIC) que le han seguido, y las que aún están por llegar. $Y$ aunque desgraciadamente no están ni mucho menos implantadas en las aulas actualmente, han supuesto un cambio radical produciendo que los alumnos tengan un papel protagonista en su aprendizaje, dándole al profesor otro rol diferente al desarrollado hasta ahora, el de asesor y guía pedagógico.

Ausubel afirmaba que "Si tuviese que reducir toda la psicología educativa a un solo principio, enunciaría éste: el factor más importante que influye en el aprendizaje es lo que el alumno ya sabe. Averígüese esto y enséñese en consecuencia". Su teoría del aprendizaje significativo (Ausubel, 1983) es sobre la que está construida la docencia actual, y un elemento imprescindible para que exista aprendizaje.

Partiendo de esta base, hemos decidido utilizar las series de TV para poder enseñar. Usaremos aquello que muchos alumnos ya conocen, como forma de construir significados nuevos. Muchos estudiantes son fans del fenómeno televisivo Juego de Tronos (2011), por ejemplo. Conocen sus personajes, su historia... y les apasiona. Saben que Ned Stark recibe la visita de Robert Baratheon, por lo que, por qué no convertir esa información que ya conocen en una forma de construir otro conocimiento. En definitiva, utilizaremos un elemento que usamos para nuestro tiempo libre y lo convertiremos en una herramienta pedagógica que los lleve a aprender los principios del protocolo y la organización de eventos. 


\section{MARCO TEÓRICO}

Las bases sobre las que hemos construido esta investigación han sido fundamentalmente dos: el protocolo y las series de TV desde una perspectiva pedagógica.

\subsection{Protocolo}

El protocolo es tan antiguo como lo es la sociedad humana. Desde el momento en el que el ser humano convive en grupos, se hacen necesarias unas reglas que garanticen la convivencia pacífica entre todos sus miembros. Si por algo se ha caracterizado el ser humano a lo de la historia, es por no tener una naturaleza anárquica. Incluso hoy en día, cuando se estudian tribus que no han tenido nunca contacto con otros grupos sociales, se puede ver cómo existen unas normas para garantizar la cohabitación. Pero a pesar de la antigüedad e importancia de esta materia, muy pocas son las investigaciones que se tienen al respecto.

Orozco López (2016) sostiene que, para entender el protocolo y conocer sus orígenes, nos hemos de remontar al momento en el que el ser humano decide vivir en sociedad, y por lo tanto, necesita organizar las relaciones entre los distintos individuos que la integran para evitar conflictos. En una sociedad gregaria y que necesita distribuir espacios y recursos, el ser humano debía, en algún momento, empezar a establecer normas que determinaran quiénes ocupaban los lugares más seguros o quiénes obtenían la comida más nutritiva, en detrimento de aquellos que eran obligados a quedarse en las zonas menos seguras y a consumir lo que los otros no querían. En palabras de Orozco López (2016) "las sociedades necesitan el protocolo, que coloca a cada cual en el lugar que le corresponde y premia las conductas valiosas de acuerdo con una escala de valores que cada sociedad y cultura ha elaborado, según sus necesidades" (p.7).

El primer texto sobre protocolo del que tenemos constancia es El Código de Hammurabi. Data del año 1750 a.C. aproximadamente y es un bloque de basalto tallado de unos 2,50 m. de altura por 1,90 m. de base. Fue escrito en lengua Acadio y consiste en un conjunto de leyes hechas para regular la vida cotidiana del primer Imperio Babilónico y nos interesa en esta investigación por los tres escritos relacionados con el protocolo. De todas sus indicaciones, hay dos que podríamos aplicar a la actualidad en cualquier manual de protocolo: "traten con máximo respeto y cortesía a todos los ciudadanos del reino, cualquiera que sea su nivel social" y "pongan el mayor cuidado en realizar bien y de un modo justo las ceremonias del reino, porque esto contribuye a la felicidad, prosperidad y paz de todos los súbditos". El código de Hammurabi, además, establecía que el encargado de garantizar que se cumplieran todas las leyes referentes al protocolo era el Sumo Sacerdote, que hoy en día equivaldría al Jefe de Protocolo de cualquier empresa o institución.

Por tanto, el protocolo es una disciplina inherente al ser humano, puesto que no está en su naturaleza vivir anárquicamente, y contribuye a generar una convivencia social pacífica. Pero además, construye, genera y describe las estructuras sobre las cuales se vive, determinando un orden para esa convivencia positiva de la que hablábamos. Este último aspecto, lo podemos ver claramente en el Real Decreto 2099/83 que rige el orden de precedencias en los actos organizados por las instituciones españolas. Si lo leemos con 
detenimiento, será fácil poder describir cuáles son las principales estructuras con las que cuenta nuestro país (España).

Una vez hemos analizado el origen del protocolo, y cuál es su función principal en la sociedad, debemos analizar cuáles son sus fuentes. A este respecto hay dos autores a los que nos gustaría citar. Por un lado Sánchez González (2011) y por el otro, Barquero Cabrero, Ramos Fernández, y Medina Elizondo (2013). De acuerdo con ellos podemos afirmar que son dos:

Por un lado, las leyes. Generadas por los gobiernos para su aplicación en los actos de carácter oficial, y que nos permiten la regulación en los mismos, como por ejemplo la ordenación de los cargos institucionales en los eventos.

La segunda fuente, son los usos y costumbres sociales. Estos corresponden a aquellas reglas que decíamos al principio, que se generan para convivir socialmente, y que todos han de conocer. No están reguladas por ley, pero se siguen, puesto que es lo que se exige a todos los miembros de una determinada comunidad para ser aceptados en el misma. Se trata de un acuerdo tácito.

Fuente Lafuente (2010) califica el protocolo como necesario en todos los sectores de la sociedad actual: el mundo de la empresa, del deporte, la cultura... Este mismo autor hace una reflexión sobre el estado actual del protocolo, enmarcándolo en una crisis conceptual. Esta ciencia se encuentra en un momento de cambios. En el s. XX ha sufrido un cambio cualitativo importante, pasando de ser una herramienta tradicionalmente al servicio de las instituciones públicas tradicionalmente, para dar el salto al mundo de la empresa privada. Esta ha adoptado las formas que le son propias a las instituciones, para convertirlas en suyas en aras de generar un discurso para sus públicos.

Finalmente, terminamos este marco teórico ofreciendo una definición actual del concepto protocolo de Delmás Martín y Gómez Hernando (2019):

El protocolo es una disciplina científica transversal que define las estructuras sociales y las normas generadas por uso, costumbre, tradición o legislación de las que se dota una sociedad para garantizar y facilitar la convivencia en armonía de todos sus miembros. Como herramienta de comunicación que se aplica a todos los ámbitos sociales, el protocolo toma especial relevancia en la organización de actos, tanto públicos como privados, donde proporciona técnicas que permiten hacer tangible lo intangible. (p.18) 


\subsection{Series de TV: elemento pedagógico y de tiempo libre}

Las series de TV son un elemento concebido para el tiempo libre, por tanto, habría que responder a la pregunta: de ¿qué sentido tiene usar las series de TV en las aulas? La respuesta tiene varias vertientes:

En primer lugar, por el denominado fandom ${ }^{2}$, del que forman parte muchos estudiantes. En esta línea, Moreno Armenteros (2017) afirma que siempre se ha concebido el cine como un elemento para el tiempo de ocio y entretenimiento, pero que, usado como elemento de aprendizaje de forma estratégica conseguimos alumnos inquietos, con ganas de aprender e implicados. En definitiva, habla del factor motivador que tiene este medio para los discentes.

En segundo lugar, otra perspectiva es la aportada desde el trabajo de León Cruz (2015), quien escribió un artículo donde reflexionaba sobre la actual necesidad de innovar en las aulas, y a este respecto afirma que, si se quiere introducir un cambio educativo en las mismas, este debe partir desde el compromiso con los estudiantes. Para ello, estos necesitan tomar un papel activo en su proceso de aprendizaje durante los diez años que desarrollan su educación obligatoria, y en los cuales, no solo deben adquirir autonomía y desarrollar sus capacidades intelectuales, sino que además, tienen que ver la utilidad y aplicabilidad real de aquello que aprenden en las aulas.

En tercer lugar, la siguiente perspectiva la tenemos de la mano de los autores Lorenzo-Lledó y Roig-Vila (2017), citando a Ferrés (2006) donde afirman que, en la sociedad actual lo audiovisual ha tomado un papel protagonista, pero las aulas siguen sin contemplar esta competencia y como consecuencia, se ha generado una distancia muy amplia entre los entornos de aprendizaje y la vida cotidiana de los estudiantes. Y en la misma línea va Gutiérrez Romero (2017), quien en su estudio sobre el cine como herramienta para la enseñanza de literatura afirma que:

Somos y formamos parte de la cultura de la imagen; cultura que ha venido cobrando una fuerza importantísima y cuyo poder es una característica de la temporalidad que habitamos. Por lo anterior, una cultura centrada en el poder de lo escrito se presenta como insuficiente para abordar conocimientos, por ejemplo, de corte lingüístico en la formación de los estudiantes, se hace necesaria la alfabetización de la mirada [...]. (p.27)

${ }^{2}$ Colectivo que centra gran parte de sus actividades sociales, creativas y discursivas en torno a las series de televisión de culto. Colectivo que centra gran parte de sus actividades sociales, creativas y discursivas en torno a las series de televisión de culto. 


\section{DESARROLLO}

\subsection{Origen y descripción de la investigación y del trabajo de campo}

En julio de 2016, durante un viaje en coche, caí en la gran cantidad de ejemplos sobre protocolo que se pueden ver en las series de TV actuales. Por lo que pensé, ¿por qué no crear un videoblog donde explicar esos ejemplos de una forma mucho más cercana y amena para todo el público? En octubre de ese mismo año salió on-line el primer capítulo de un canal que se denomina Spoilers de Protocolo (Delmás Martín, 2016, octubre 5), y que a día de hoy ya cuenta con más de 2.500 visualizaciones en sus vídeos. Por consiguiente, ¿cuál era la siguiente fase? Pasar a utilizar el recurso en las aulas con el objetivo de formar a profesionales de la materia de una forma amena, atractiva y que supusiera una mejora en términos cualitativos para el proceso de aprendizaje.

Para ello, se llevó a cabo una investigación a través de la cual transformamos las series de TV en una herramienta docente para enseñar protocolo y eventos. La investigación está enmarcada dentro de las empíricas y exploratorias. En este escenario el paradigma ha sido interpretativo y, siguiendo el esquema de McMillan y Schumacher (2005) de corte cualitativo e interactivo como estudio de caso. El trabajo de campo para este proceso de investigación se ha llevado a cabo en las aulas de la Universitat Jaume I. Tuvo lugar durante las clases del segundo semestre, entre enero y marzo de 2018.

El uso de las series de TV en el aula se llevó a cabo durante una clase de tres horas de practicas que tenían los alumnos. Esta nueva metodología de aprendizaje la pusimos en práctica durante cinco clases, donde lo que hacíamos era visualizar una escena y posteriormente los alumnos, por grupos, debían de deconstruirla. El docente, en un rol de asesor y guía docente, estaba con los grupos con el fin de asistirles. Este gráfico es el resumen de las clases:

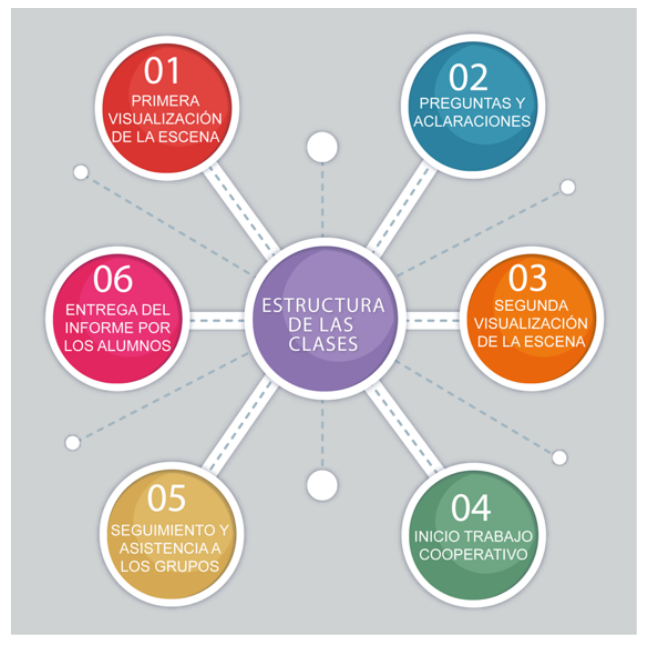

Imagen 1: Esquema de la estructura de clases Fuente: elaboración propia 
Esta estructura se ha mantenido durante cuatro semanas donde se han visualizado las escenas para el análisis de los estudiantes. La última semana, llevamos a cabo el trabajo a la inversa. Ellos debían de crear un acto.

Para poder llevar a cabo este trabajo de deconstrucción de escenas, se les ha proporcionado a los alumnos una ficha. Esta imagen muestra un resumen de la misma:

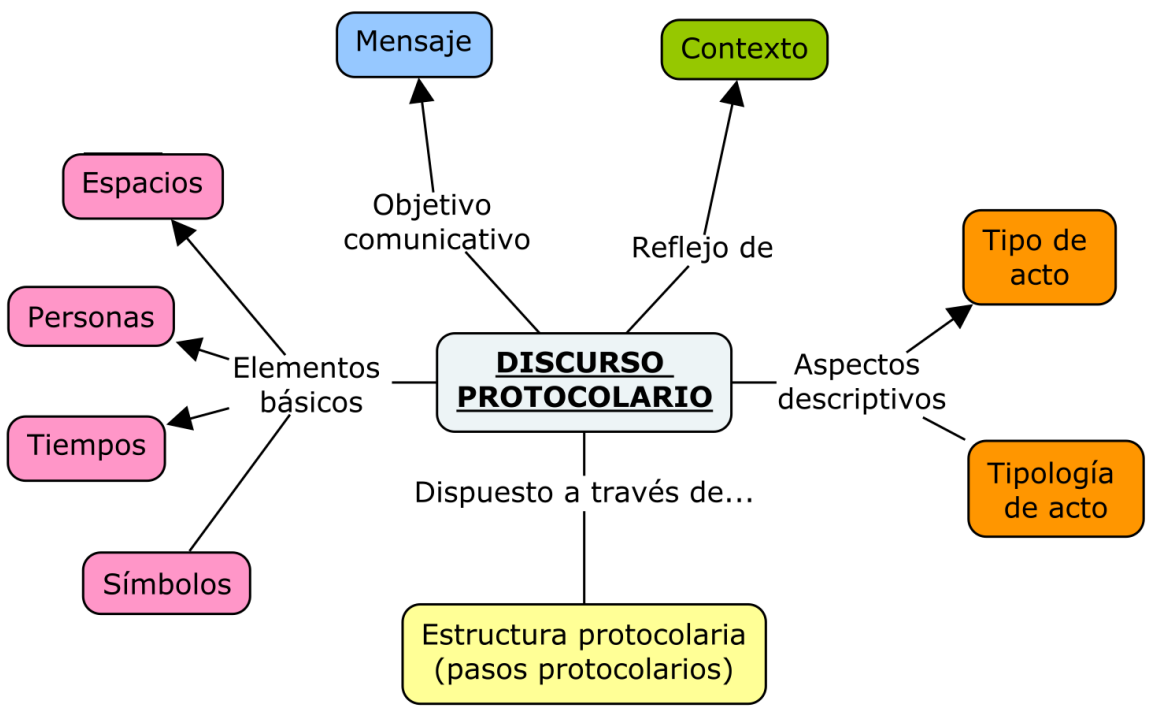

Imagen 2: Mapa conceptual explicativo de la ficha de análisis Fuente: Elaboración propia.

\subsection{Resultados y análisis de datos}

El primer cambio que se ha notó fue respecto a la asistencia. La profesora Bernad percibía que, el uso de las series de TV no solo contribuyó a generar un grado muy alto de presencia en el aula, respecto a años anteriores, sino a centrar la atención de los alumnos durante toda la clase. Afirmaba que otros años, a la mitad de la clase "desconectaban" de lo que se estaba haciendo, y mediante estos nuevos recursos, se consiguió mantener su atención las tres horas que dura la clase de práctica. En esta línea, sostenía, además, que no se hizo descanso en las tres horas de clase, pero que no lo pedían ni parecía necesario.

Si observamos detenidamente los resultados obtenidos durante las cuatro semanas, podemos afirmar que son positivos, y que aún teniendo en cuenta que el periodo de aplicación ha sido muy corto, van encaminados al propósito que nos marcábamos al inicio de la investigación.

En lo que respecta a la evolución de la identificación del tipo de acto, público, privado o mixto, la herramienta ha ayudado, sin lugar a dudas, a los alumnos a asentar estos conocimientos. Tras la primera semana, el cambio fue muy positivo y los estudiantes aprendieron a diferenciar entre los tres términos en función de lo que veían en las escenas seleccionadas. 
Si hablamos de la identificación del tipo de protocolo de la escena, es decir, social, oficial, eclesiástico, etc. la evolución también ha sido muy buena. Hemos pasado de tres casos incorrectos, a uno solo en las dos semanas siguientes, y a ningún caso erróneo en la última.

En lo que respecta a hacer un resumen de la escena visualizada, y por tanto, un elemento de la Competencia Digital de los estudiantes, hemos podido ver como los datos han sido muy positivos. La primera semana tuvimos siete casos incorrectos, la segunda tres, y las dos últimas tan solo uno. Por ello, las series de TV han tenido un efecto muy positivo en este aspecto. Han ayudado a los alumnos a desarrollas este aspecto de la Competencia Digital.

Si hablamos de obtener el resumen de protocolo, es decir, de los diferentes pasos que se dan desde el punto de vista del discurso protocolario para la construcción de un acto, los resultados también han sido muy buenos. La primera semana tuvimos un total de seis casos incorrectos, pasando a tres en la segunda, uno en la tercera, y a cero en la última semana.

Este desenlace es uno de los más importantes para esta investigación, ya que el determinar los pasos a partir de los cuales se va a construir un evento, es una de las fases más importantes a las que se tendrán que enfrentar en su desarrollo profesional posteriormente a terminar su etapa en la universidad.

Seguidamente, vamos a ver los resultados que arrojan los elementos básicos con los que se construye un acto: espacios, personas, tiempos y símbolos.

Empezaremos por los espacios, y a este respecto, hemos de decir que la evolución ha sido moderadamente buena. Aunque la progresión en las dos primeras semanas fue buena, tuvimos una evolución negativa en la tercera semana, que terminó siendo positiva en la última semana.

El apartado personas ha tenido una relación directa con el número de personajes con los que contaba la escena, y que eran relevantes en el discurso protocolario. Cuando mayor ha sido el número de personas a analizar, como por ejemplo la segunda semana con once elementos, mayor el número de casos erróneos que se registraban entre los grupos.

Similar conclusión es la que hemos conseguido en el apartado espacios. Cuando mayor era el número de ellos a analizar por los alumnos, más casos incorrectos hemos conseguido.

En lo que respecta a tiempos y símbolos la evolución no ha sido positiva. Los alumnos tienen dificultades para poder identificarlos, lo que nos lleva a pensar que para un progreso positivo en estos aspectos, necesitamos más clases de deconstrucción del discurso protocolario, y además, hacer más hincapié en ellos en la parte teórica. 
Por último, y respecto a los resultados obtenidos de los datos de la ficha de análisis, tenemos uno de los pilares fundamentales, y que es el elemento indispensable del protocolo actual: identificar el mensaje del acto. En esta perspectiva, la evolución ha sido positiva, pero lenta. Hemos pasado de ocho casos incorrectos la primera semana, a seis en la última.

Si buscamos conclusiones a partir de los datos de la práctica de creación de actos, de la quinta semana, y los relacionamos con los anteriormente descritos, la eficacia del método pedagógico empleado, parece más positiva aún. En todos los apartados del informe, salvo en dos de ellos, solo hemos obtenido entre uno y tres resultados incorrectos. Incluso en aquellos apartados como tiempos y símbolos, donde los resultados con las escenas no habían sido muy buenos, en este caso sí lo fueron.

\section{CONCLUSIONES}

Del mismo modo que, desde el punto de vista de la comunicación organizacional las empresas tanto públicas como privadas, buscan la mejor herramienta a partir de la cual, hacer llegar a sus diferentes públicos sus mensajes, en la docencia ha de ocurrir lo mismo. Se necesita de un cuerpo docente que vaya introduciendo las herramientas TIC en las aulas para que los estudiantes se sientan más conectados con el proceso de aprendizaje y aumente su efectividad. Con todas las herramientas existentes al alcance del profesorado, y el nuevo contexto que tienen los discentes, no tiene sentido seguir con metodologías pedagógicas que no responden a las necesidades actuales.

Respecto a la ficha de análisis, consideramos que es adecuada para que los estudiantes puedan aprender a deconstruir y construir el discurso protocolario. Que ha sido un elemento adecuado en el proceso de enseñanza, y que gracias a ella los alumnos han conseguido asentar y asimilar los elementos básicos del protocolo. La evolución en la mayoría de los apartados ha sido progresiva y positiva, pero necesitamos generar otra estrategia de selección de escenas para favorecer aún más el aprendizaje, ampliar el periodo de implantación para consolidarlo, y buscar una metodología pedagógica que cambie la clase magistral.

Por tanto, tras la experiencia en clase y los resultados vistos, consideramos que enseñar protocolo a través de escenas de series de TV ha sido un acierto. La experiencia ha sido muy satisfactoria desde el punto de vista de los profesores y los estudiantes. Además de que, las escenas, han ayudado a los alumnos a materializar lo que será su futura profesión e ir más allá de la parte teórica.

\section{BIBLIOGRAFÍA}

Barquero Cabrero, J. D., Ramos Fernández, F., \& Medina Elizondo, M. (2013). Protocolo y relaciones Públicas en la sociedad pluralista. Usos, normas y reglas en actos públicos y privados. (Furtwangen). Barcelona: ESERP, School of business and social sciences. Colección ciencias económicas y sociales.

Delmás Martín, D., y Gómez Hernando, M. (2019). Spoilers de Protocolo. (Editorum, Ed.) (1 Edición). Madrid: Editorum. 
Fuente Lafuente, C. (2010). Protocolo Oficial (5 Edición). Ediciones Protocolo. Colección Área de Formación.

Gutiérrez Romero, C. C. (2017). Cinematografías de formación: una experiencia con el cine y la literatura en el aula universitaria. Universidad de Antioquia, Medellín (Colombia). Obtenido de http://ayura.udea.edu.co:8080/jspui/handle/123456789/2548

León Cruz, P. (2015). Docere delectando: series, películas y videojuegos como herramientas de innovación docente. Opción, Especial 4, 656-665. Obtenido de http://www.redalyc.org/pdf/310/31045569040.pdf

Lorenzo-Lledó, A., \& Roig-Vila, R. (2017). El cine como recurso didáctico: percepciones de los estudiantes del Grado de Maestro. In Investigación en docencia universitaria. Diseñando el futuro a partir de la innovación educativa (Ediciones, pp. 305-313). Alicante: Octaedro. Obtenido de http://rua.ua.es/dspace/handle/10045/71134

Moreno Armenteros, L. (2017). El cine como recurso didáctico enseñar Trabajo para inglés en Educación Primaria ( Tercer ciclo ). Jaen.

Orozco López, J. D. D. (2016). Protocolo para la organización de eventos. (I. Editorial, Ed.) $\left(1^{\mathrm{a}}\right)$. Antequera: IC Editorial.

Sánchez González, D. del M. (2011). Fundamentos del ceremonial y del protocolo. Editorial Síntesis. 